\title{
New technologies and role of direct surveys in the production of Official Statistics
}

\section{Loredana De Gaetano, Pasquale Papa}

ISTAT - Italian National Statistical Institute, Rome, Italy.

\begin{abstract}
The technological development applied to statistical data collection processes, that has taken place in recent years, and the increasing availability of alternative statistical sources, notably administrative and so-called "sensor", is leading to a profound revision of the role of direct surveys, also in the context of Official Statistics.

The objective of this article, based on the experiences in progress in ISTAT (Italian National Statistical Institute) is to evaluate the status of the transition towards a more modern, efficient and sustainable way of conducting direct surveys, in a set of specific areas, providing examples and targeted analysis. This analysis will help to build a general framework towards which the collection of Official Statistics data will converge in the next years.

In the above mentioned framework the analysis will mainly involve three converging macro areas: a) individuation of efficient management set-up of data collection processes; b) application of innovative techniques in the data collection of traditional direct surveys; $c$ ) aspects related to the availability of new alternative sources to those currently used in the production of official statistics.
\end{abstract}

Keywords: smart surveys; data collection; centralised data collection; administrative sources; sensor data; data collection statistical portals. 


\section{Introduction}

The opportunities offered by the application of new technologies to the field implementation of direct surveys, that has taken place in recent years and the increasing availability of alternative statistical sources mainly in the form of administrative archives, and other sources not directly produced for statistical purposes is leading to a profound revision of the role of direct surveys, also in the context of Official Statistics.

At the same time, various trends have emerged in the social and economic contexts of many countries which tend to reduce the participation of the statistical units involved in the surveys, recording average decreasing response rates. The awareness of the increasingly less sustainable statistical burden that official statistical surveys exercise on respondents has also developed, showing the growing need to reduce it.

\section{Investigated areas}

The effects of all these trends led to the development of new strategies in the management of data collection in Official Statistical processes, summarized in the following thematic areas:

\subsection{Data collection processes management set-up}

The first step consists of adopting management solutions that allow greater control over the data collection processes conducted in the context of Official Statistics. An example in this regard is the adoption of an integrated and centralized data collection approach. This solution involves greater efficiency of data collection procedures and control on total direct survey quality. A second step concerns the development of generalized survey management systems, as much as possible oriented towards integration and rationalization that allow making all the activities required to the various actors involved in the survey data collection processes more coordinated and efficient. The adoption of multi-technical approaches in order to provide tools that adapt to the different types of users involved in the surveys and their structural characteristics (age and cultural level for individuals and size and sector for companies) is also very important.

\subsection{Application of advanced techonologies for data collection purposes}

Technical development allows the application of advanced technologies to direct survey data collection according to an approach that can be defined as "smart". At the same time in the last years several National Statistical Institutes have started designing "Portals" for data collection. Development of data collection Portals aimed at optimizing relations with respondents and providing specific services aimed at rationalizing and simplifying the statistical requirements. These portals are particularly effective to encourage the development of the CAWI technique which allows respondents to fulfill the statistical requirements by 
filling in web questionnaires. Portals also involve the development of a series of user-oriented facilities aimed at simplifying the task required of the respondent (e.g. centralized inbound and outbound Contact Center services). ISTAT (Italian National Statistical Institute) implemented a portal for data collection to all companies involved in economic surveys starting from 2015 (Portale Statistico delle imprese). It involved the exploitation of the CAWI technique, reducing the costs for the remuneration of esternal companies used for the management of CATI and CAPI techniques. A single portal is currently being designed for the units involved in all direct surveys. A theme on which Istat is also investing is that of the use of artificial intelligence to manage some repetitive phases of the data collection process, e.g. automated sorting requests for assistance coming from the units involved in the surveys to the correct recipients and automatic response to repetitive questions coming from respondents.

\subsection{Use of alternative sources for statistical purposes}

The development of alternative sources mainly consists of administrative data that can be used for statistical purposes. In this regard, ISTAT has launched two parallel initiatives: the first consists in the design of an integrated system of registers, based mainly on administrative sources, in order to support and complement the direct survey-based data collection. The second initiative concerns the use of administrative archives for the specific needs of specific direct surveys. All this requires the development of synergies between entities producing official statistics or owners of administrative sources used for statistical purposes. In addition to administrative sources, other data sources can be used which are already available for different purposes: e.g. big data and sensor data. In this regard, Istat is planning specific techniques for retrieving information from these data sources.

\section{Conclusions}

The main trends in the field of data collection for Official Statistics, which involves management, technical and contextual aspects imply a radical revision of the role of direct surveys. In fact the role of direct surveys tends more and more to be limited to sectors and situations where alternative sources are not available or to measurement of distortions of the alternative sources themselves. In this perspective, the direct surveys must become smaller and more targeted and qualitative, and the need to produce instruments aimed at measuring and controlling the Total Survey Error (TSE) which includes both the sample and non-sample components of the statistical error still remains a topic of great interest. In the above mentioned framework the objective of this article, based on the experiences in progress in ISTAT, is to evaluate the progress of the transition in each of the identified areas, providing examples and targeted analysis. This analysis will help build a general framework towards which the collection of Official Statistics data will converge in the next years. The transition 
also tends to meet two basic requirements for Official Statistics of the future, that is reducing costs, with a view to promoting the social sustainability of official statistical systems.

\section{References}

Bellini G., Monetti F., Papa P. (2018), The impact of a centralized data collection approach on response rates of economic surveys and data quality: the Istat experience. Q2018, European conference on quality in official statistics, Kraków

Bellini G., Cecconi N., De Gaetano L., Monetti F., Papa P. Ranaldi R. (2018),Centralizing data collection implementation: the Istat experience: Data Collection Workshop 'Resourceful Data Acquisition- UNECE Geneva

De Gaetano L., Digrandi A., Papa P. (2018), A territorial model for data collection implementation. Q2018, European conference on quality in official statistics, Kraków

Fazio N.R, Murgia M., Nunnari A. (2013), The business statistical portal: a new way of organizing and managing data collection processes for business surveys in Istat, Unece Conference of european statisticians.

Istat (2017), Mapping delle attività della DCRD nell'ambito dello schema concettuale di riferimento internazionale GSBPM. Delibera D16 49 DIRM2017.

Istat (2016), Istat's modernisation programme,

https://www.istat.it/it/files//2011/04/IstatsModernistionProgramme_EN.pdf

Lise Rivais, Marc St-Denis, Susan Lensen (2013), Centralising data collection at Statistics Canada. Seminar on Statistical data collection. Unece - Conference of european statisticians.

Saraiva dos Santos P. and Moreira A. (2013). Creating a data collection department: statistics portugal's experience. Seminar on Statistical data collection. Unece - Conference of european statisticians.

Signore M. (2017) GSBPM and other international standards MedStat training on GSBPM, Istat - $\quad$ Rome (2017-07). Available at https://statswiki.unece.org/display/GSBPM/GSBPM+Training+Materials

Signore M. (2017) GSBPM how to use and implement MedStat training on GSBPM, Istat Rome (2017-07). Available at https://statswiki.unece.org/display/GSBPM/GSBPM+Training+Materials

Marske R. And Stempowski D. M. (2009), Company-Centric Communication Approaches for Business Survey Response Management, Statistics Canada Symposium 2008: Data Collection: Challenges, Achievements and New Directions. Available at https://www150.statcan.gc.ca/n1/en/pub/11-522-x/2008000/article/10983-eng.pdf?st=0IwAKvz

Unece Statistics wiki. Generic Statistical Business Process Model - GSBPM. http://www1.unece.org/stat/platform/display/metis/The+Generic+Statistical+Business+ Process+Model

Groves, Robert, Floyd J Fowler, Mick Couper, James Lepkowski, Eleanor Singer, and Roger Tourangeau. 2009. Survey Methodology. 2nd ed. Hoboken, NJ: John Wiley \& Sons. 
Groves R.M. and Lyberg L. (2010) Total Survey Error: Past, Present, and Future Public Opinion Quarterly, Volume 74, Issue 5, 2010, Pages 849879, https://doi.org/10.1093/poq/nfq065

Biemer P. Total survey error design, implementation, and evaluation Public Opinion Quarterly, Volume 74, Issue 5, 2010, Pages 849-879.

Geon Lee G., Benoit-Bryan J. and Johnson T. P. (2012), Survey Research in Public Administration: Assessing Mainstream Journals with a Total Survey Error Framework, Public Administration Review, Vol. 72, No. 1 (JANUARY/FEBRUARY 2012), pp. 8797

Jedinger A., Watteler O. and Förster A. (2018), Improving the Quality of Survey Data Documentation: A Total Survey Error Perspective- Data - Open Access Journal 